\title{
A CONSTRUÇÃO DISCURSIVA DO CORPO FEMININO NA REVISTA JORNAL DAS MOÇAS DA DÉCADA DE 50
}

\author{
Lara da Silva Cardosoㅜ; Palmira Virgínia Bahia Heine ${ }^{2}$ \\ 1. Bolsista PIBIC/CNPq, Graduanda em Licenciatura em Letras Vernáculas, Universidade Estadual de Feira de Santana, e- \\ mail: laracardooso@ hotmail.com \\ 2. Orientadora, Departamento de Letras e Artes, Universidade Estadual de Feira de Santana, e-mail: pavibheine@gmail.com
}

PALAVRAS-CHAVE: Discurso; Corpo feminino; Jornal das Moças.

\section{INTRODUÇÃO}

O Brasil nos Anos Dourados, período que vai de 1945 a 1964, passou por importantes mudanças. A ampliação do poder estatal, o avanço na industrialização e a criação do salário mínimo impulsionaram o consumo e o poder econômico dos brasileiros. A influência da cultura norte-americana trouxe inspirações sobre liberdade e comportamento aos jovens da época, que desejam viver o "American way of life". Apesar desse grande crescimento econômico e industrial, no que diz respeito aos valores e concepções de família e papéis de gênero, a sociedade brasileira tentou manter suas concepções intactas.

A mulher, na década de 50 teve sua educação mais valorizada e houve o surgimento de maiores oportunidades de emprego para o sexo feminino. Entretanto, ainda assim, as mulheres eram vistas a partir das concepções arraigadas, das décadas anteriores, de dedicação ao lar e aos filhos. Segundo Pinsky (2014, p. 18)

"A família conjugal é o modelo dominante. Nas casas de classe média, as famílias são de fato tipicamente compostas por pai, mãe e filhos(...). A autoridade máxima ainda é conferida ao pai, 'o chefe da casa', e garantida pela legislação que reconhece o trabalho masculino como a principal fonte de recursos da unidade doméstica. As leis também enfatizam a imagem da mulher exclusiva ou prioritariamente dedicada ao lar e à procriação".

O contexto de modernização pelo qual passava o Brasil ajudou alguns veículos midiáticos, tais como a revista e o rádio, a se tornarem meios de comunicação de massa e a propagarem as concepções da época sobre a constituição da sociedade brasileira. Às mulheres eram produzidas revistas exclusivas, denominadas de revistas femininas, que abordavam assuntos considerados na época de interesse feminino, segundo o padrão de sociedade dos anos 50.

A revista Jornal das Moças foi um periódico bastante aclamado pelo público ao qual se dirigia às mulheres, alcançando o primeiro lugar entre as revistas femininas semanais no período referido (PINSKY, 2014). Autointitulado como "a revista da mulher no lar e na sociedade", o Jornal das Moças abordava diversos assuntos referentes ao universo feminino da época, como corte e costura, moda, dicas de relacionamento e beleza. Desse modo, essa revista torna-se importante fonte de pesquisa para compreender e analisar os discursos sobre o corpo feminino nos anos de 1950. Através do contato com os períodos referidos, este trabalho foi desenvolvido com o objetivo de Analisar os sentidos relacionados ao corpo feminino produzidos pela revista Jornal das Moças na década de 50 a partir da teoria francesa de Análise do Discurso.

\section{MATERIAL E MÉTODOS OU METODOLOGIA (ou equivalente)}

A metodologia utilizada para a execução do objetivo deste trabalho seguiu as etapas de análises discursivas, conforme a ADLF (Análise de Discurso de Linha Francesa), desenvolvida por Michel Pêcheux (1975). Contemplando aspectos basilares de diferentes disciplinas - a Linguística, o Marxismo e a Psicanálise - Pêcheux desenvolveu uma teoria 
capaz de analisar discursos, estes, por sua vez vistos "de modo mais geral, de um 'efeito de sentidos' entre os pontos A e B" (PÊCHEUX, 1975, p. 82).

A partir da leitura e análise de exemplares do período Jornal das Moças da década de 1950, foram estudados os efeitos de sentidos produzidos pelos discursos e as condições de produção da revista. O não-dito e o interdiscurso, conceitos propostos por Pêcheux (1975) também foram levantados neste trabalho, buscando demonstrar de que forma os discursos anteriores aos gerados pela revista nos anos 50 interferem na produção dos discursos da década referida.

Concomitantemente, foram realizadas pesquisas sobre o funcionamento da ideologia, a partir das noções de Althusser (1985) e como ela determina quais formações discursivas (FDs) o sujeito se insere e qual discurso deve ou não deve ser dito, a partir da identificação do sujeito em determinada posição.

\section{RESULTADOS E/OU DISCUSSÃO (ou Análise e discussão dos resultados)}

A partir das propagandas encontradas nos semanários dos primeiros meses de 1950, percebe-se os efeitos de sentidos gerados e direcionados para uma normatização do corpo feminino. As análises foram realizadas com publicidades presentes nos periódicos de Janeiro e Março de 1950. As reportagens e matérias do Jornal das Moças referentes ao corpo da mulher, voltam-se para a necessidade de "consertá-lo" através do uso de um sutiã, como na figura 01 .

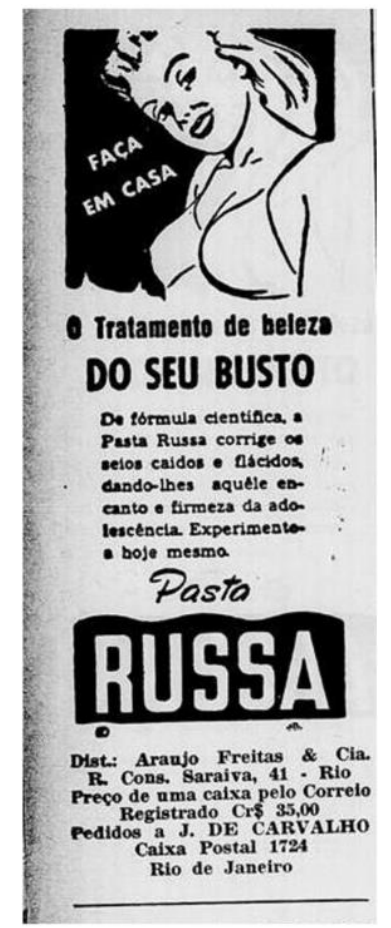

Figura 01: “O tratamento de beleza DO SEU BUSTO. De fórmula científica, a Pasta Russa corrige os seios caídos e flácidos, dando-lhes aquele encanto e firmeza da adolescência. Experimente-a hoje mesmo".

Esses discursos geram sentidos que retomam o interdiscurso, conceito desenvolvido por Pêcheux (1975), o qual indica que um discurso é sempre constituído por discursos anteriores, numa relação de confronto ou retomada. A parte do interdiscurso retomada pela revista nessas propagandas é a que a mulher precisa de um 'conserto', pois seu corpo físico natural não atende ao padrão de beleza imposto em 1950 para o sexo feminino.

A imagem também retoma partes do interdiscurso referente ao destino da mulher: o casamento. As condições de produção da revista, nos anos 1950, destinam as moças a 
casarem-se cedo: Pinsky (2014) aponta que, na década de 50, a mulher solteira com mais de 25 anos era considerada ultrapassada. O objetivo da Pasta Russa é "corrigir seios caídos e flácidos" que fogem do padrão de beleza imposto na época. A jovialidade é o desejo da mulher desse período, que estava inserida em determinada ideologia que negativava a velhice. $\mathrm{O}$ item a ser vendido ainda promete um "encanto e firmeza da adolescência", sendo possível produzir um sentido de naturalização da atratividade juvenil.

A figura 02 analisada também aborda a necessidade de correção do corpo feminino e de cuidado redobrado com o envelhecimento corporal e as suas consequências para o convívio em sociedade.

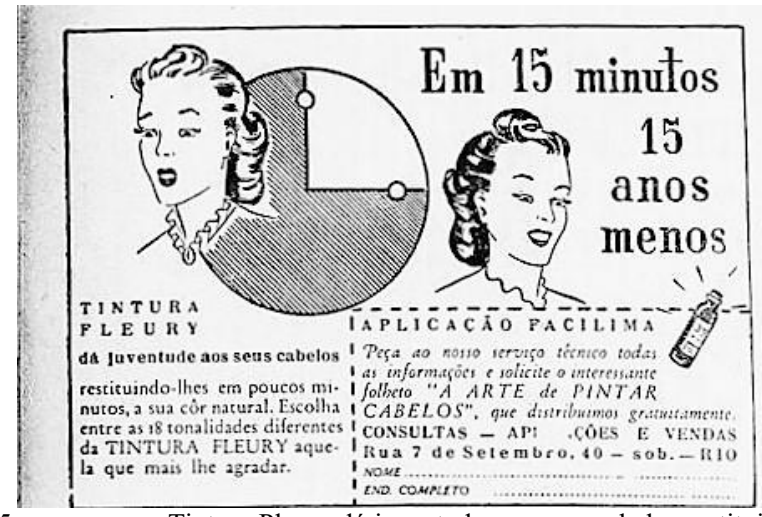

Figura 02: "Em 15 minutos 15 anos menos. Tintura Pleury dá juventude aos seus cabelos restituindo-lhes em poucos minutos, a sua côr natural. Escolha entre as 18 tonalidades diferentes da TINTURA FLEURY aquela que mais lhe agradar".

Ambos os anúncios indicam que as mulheres devem estar atentas ao processo de envelhecimento, buscando tardá-lo, através de tintas, como na figura 02 , e modelos ajustáveis de sutiãs, conforme a figura 01 .

A figura 01, relativa ao busto, exalta a naturalidade dos seios comuns na adolescência. E a figura 02, sobre cabelos, exalta a beleza da cor "natural". A tinta serve não para mudar a cor, mas sim para volta-lo ao aspecto "natural". A naturalidade feminina deixa de representar o processo biológico ocorrido no corpo da mulher e passa a ter um outro sentido, um efeito metafórico, que, segundo Pêcheux (1975) é produzido por uma substituição contextual, produzindo um deslizamento de sentido.

É natural ao corpo feminino, portanto, somente aquilo que se encaixa nos padrões estéticos dos anos 50, período em que existiam determinadas condições de produção que influenciaram nos discursos produzidos pela revista. O envelhecimento, já considerado para a mulher a partir dos 25 anos, deixa de ser natural, passando a ser evitado a todo custo pelas mulheres, as quais necessitavam atender aos modelo de beleza para atingir seus objetivos: $o$ casamento e a maternidade.

\section{CONSIDERAÇÕES FINAIS (ou Conclusão)}

A mídia, especificamente a revista Jornal das Moças teve grande influência na difusão da ideologia dominante na década de 50, pois, apesar das mudanças ocorridas no Brasil no cenário de 1950, as concepções de mulher e de família eram mantidas pelas reportagens e propagandas do Jornal das Moças.

A revista filia-se a uma formação discursiva que aponta para a necessidade de adequação do corpo feminino aos padrões de beleza para que a mulher seja considerada bonita, segundo os princípios da época. O cuidado com a estética era fundamental, uma "obrigação", e cabia à mulher o cuidado com a estética.

A construção do que é ser mulher, a partir dos sentidos gerados pelos discursos do Jornal das Moças de 1950, ocorre através da normatização do corpo feminino. Com conselhos de beleza, a revista aponta o que deve e o que não deve ser feito para se obter uma pele ideal. $\mathrm{O}$ não cumprimento dos conselhos resulta numa estética desagradável, segundo a 
revista, e que tem consequências na realização do objetivo da mulher dos anos de 1950: o casamento.

Assim, percebe-se a importância de analisar, conforme a Análise de Discurso de Linha Francesa, as propagandas do periódico Jornal das Moças nos anos de 1950 a fim de investigar e discutir as relações de gêneros na sociedade, já que, conforme Pêcheux (1975), todo discurso é elaborado através de sentidos retomados e esquecidos de outros discursos já realizados. A normatização do corpo feminino, através do estabelecimento de regras sobre o que pode ou não ser feito com o cabelo, com as roupas ou até mesmo o comportamento das mulheres em relação ao seu corpo, revela que as noções de beleza são geradas no discurso, momento em que os sentidos e os sujeitos se constituem.

\section{REFERÊNCIAS}

ALTHUSSER, Louis. Aparelhos ideológicos de estado: nota sobre os aparelhos ideológicos de Estado. 3 ed. Rio de Janeiro: Graal, 1985.

JORNAL DAS MOÇAS. Rio de Janeiro: Jornal das Moças, nº 01803, jan. 1950.

JORNAL DAS MOÇAS. Rio de Janeiro: Jornal das Moças, nº 01805, jan. 1950.

PÊCHEUX, Michel \& FUCHS, C. (1975). "A propósito da análise automática do discurso: atualizações e perspectivas". In: GADET \& HAK (org.). Por uma análise automática do discurso. $3^{\text {a }}$ ed., Campinas: Ed. da Unicamp, 1997, p. 163 -252.

PINSKY, Carla Bassanezi. Mulheres dos Anos Dourados. São Paulo:Contexto, 2014. 